\title{
Profiles of Dialogue for Relevance
}

\section{Douglas Walton}

Centre for Research in Reasoning, Argumentation and Rhetoric Department of Philosophy

University of Windsor

Windsor, $O N$

Canada N9B 3P4

dwalton@uwindsor.ca

\section{FABRizio MACAGNo}

\author{
ArgLab, IFILNOVA. Faculdade de Ciências Sociais e Humanas \\ Universidade Nova de Lisboa \\ Avenida de Berna 26, 1069-061 \\ Lisbon, Portugal \\ fabriziomacagno@hotmail.com
}

\begin{abstract}
In order to model relevance, we use argument diagrams (graphs), argumentation schemes, profiles of dialogue, and some tools from artificial intelligence. We show how this method helps an analyst judge relevance or irrelevance of an argument in four real examples, including a criminal trial and a parliamentary debate. We contend that this method offers important lessons for a general theory of relevance for informal logic. Some problems with notions of relevance used in linguistics are pointed out. To help build a better theory of relevance, a list of ten leading characteristics of argumentative relevance is postulated.
\end{abstract}

Résumé: Afin de modéliser la pertinence, nous utilisons des diagrammes d'arguments, des schémas d'argumentation, des profils de dialogue et certains outils employés en intelligence artificielle. Nous montrons comment cette méthode permet à un analyste de juger la pertinence ou la non pertinence d'un argument dans quatre exemples réels, y compris dans un procès criminel et dans un débat parlementaire. Nous soutenons que cette méthode offre des leçons importantes pour une théorie générale de la pertinence dans la logique non formelle. Quelques problèmes avec des notions de pertinence utilisées en linguistique sont soulignés. Pour aider à construire une meilleure théorie de la pertinence, une liste de dix caractéristiques principales de pertinence argumentative est postulée.

Keywords: profiles of dialogue, fallacies, argumentation, probative relevance, topical relevance, direct relevance, indirect relevance 


\section{Walton \& Macagno}

Relevance is a highly discussed topic in philosophy of language (Blakemore, 2002; Carston, 2004; Sperber \& Wilson, 1995; Wilson \& Sperber, 2004), linguistics (Hobbs, 1979; Lascarides \& Asher, 1993) or discourse analysis (Taboada, 2009). In linguistic pragmatics, the idea of relevance has been developed as distinct and interrelated concepts, referring to the structure of the discourse (coherence), or the socio-cognitive effects (relevance) (Giora, 1997).

On the first perspective, relevance is a relation between a set of propositions and a discourse topic, or between successive utterances (such as Elaboration, Cause, Consequence, etc.) (Asher \& Lascarides, 2003; Hobbs, 1979, 1985; Lascarides \& Asher, 1993; Wilson \& Matsui, 1998, p. 13). This approach can be used for showing whether a discourse segment is related to another, specifying or disambiguating explicit connectors, or reconstructing the implicit discourse relations (Asher \& Lascarides, 2003). However, it does not address the problem of assessing whether a premise can support a conclusion. On the second perspective, developed by Sperber and Wilson (Sperber \& Wilson, 1986; Wilson \& Sperber, 2004) (which we will refer to as $\mathrm{S} \& \mathrm{~W}$ relevance), relevance is a hearer-relative concept defined in terms of quality of information: relevant information is information that is worth the hearer's attention (Giora, 1997, $\mathrm{p}$. 18; Wilson, 1998, p. 64). S\&W relevance is defined as a ratio between cognitive effects and processing efforts, and for this reason is a hearer-relative concept, depending on the hearer's knowledge status. For this reason, it can be used for explaining relevance in information dialogue, but it does not address the problem of argumentative relevance of a premise or a piece of evidence to a conclusion, either the proximate or the ultimate (and implicit) one (Holdcroft, 1987; Ziv, 1988), in other types of dialogue such as persuasion dialogue or deliberation.

For these reason, in argumentation theory there is a great practical need to build useful methods for testing a given argument by clear criteria applicable to disputes about relevance in natural language discourse (Hamblin, 1970; Walton, 1982, 2004a, 2004b). To make a start, this paper uses four examples of objections on grounds of irrelevance found in everyday discourse in informal logic textbooks, parliamentary debates and legal argumentation. The aim of the subsequent investigation is to bridge the gap between abstract normative models of dialogue that supposedly represent how a conversation should ideally go, and real examples where there is a problem with relevance, such as the claimed instances of fallacies of relevance studied in logic textbooks (Copi \& Cohen, 2005; Walton, 1992). Our the aim is to bridge this gap by not only applying an existing method called the profiles of dialogue technique (Krabbe, 1992; Walton, 
$2004 b)$ to relevance but by extending it to enable it to apply to solving problems about relevance illustrated by these examples.

In outline, the new version of the profiles technique begins by identifying a claim that is supposedly the conclusion of an argument. The second step is to test the argument to see whether a given proposition - whose relevance needs to be assessedcan be used as part of the sequence of argumentation that moves toward proving this designated conclusion. The test utilizes some familiar argumentation tools, such as argument diagramming and argumentation schemes (Reed, Walton, \& Macagno, 2007; Walton, Reed, \& Macagno, 2008), and a tool from artificial intelligence called the Find Arguments assistant. If the automated assistant finds one or more sequences of argumentation that reach this end point, and therefore are provably relevant, it gives this information to the user and shows the path or paths to this conclusion. If it fails to find such a path, the assistant tells the user this and fills the gaps by searching for and finding possibly incomplete but useful sequences of argumentation by drawing on premises found in the commitment store of the audience.

Section 1 presents two examples of failures of relevance associated with what is called the red herring fallacy in informal logic textbooks that illustrate problems about relevance that need to be solved. The examples are meant to be simple, and hence are good introductions to convince someone of the importance of relevance objections, but the latter parts of the paper will show that they are not as simple as they initially appeared to be. Section 2 briefly sketches the existing literature on an argumentation method called a profile of dialogue, the main tool that will be applied to problematic cases of relevance in this paper. Section 3 shows how profiles of dialogue can be modeled using graph theory and some other tools in a formal and computational argumentation system called the Carneades Argumentation System (CAS). Section 4 presents a legal example called the bank robbery example. Section 5 presents an example, called the tuna fish example, from a parliamentary debate. In both instances, a particular argument that has been put forward is objected to as irrelevant by another party in the dialogue. Each of the next four sections shows how to use the new graph-theoretic model by applying the profiles method to each of the four examples in turn. The last section presents conclusions.

\section{The meanings of relevance}

For the purpose of this paper, to help the reader get started, it is best to begin with two comparatively simple examples of irrele- 


\section{Walton \& Macagno}

vance of a kind that have long been acknowledged as important in informal logic. The purpose is to show how the concept of relevance can be ambiguous, and what we need to look at when we talk about relevance in argumentation.

\subsection{Coherence, information, and probative weight}

Our starting point is an example of what was taken in a textbook to be an instance of irrelevance called the red herring fallacy. This example, presented as case study in (Walton, 2004 b), was originally from a logic textbook section on fallacies but is here presented in a simpler form that eliminates some unnecessary details.

\section{The Coffee Example}

Your friend says that Brand X coffee tastes better than Brand Y. Apparently she is ignoring the fact that Brand $\mathrm{X}$ is made by a company that also made a product that was responsible for thousands of deaths of children in undeveloped countries. Therefore, your friend is mistaken.

The error supposedly illustrated by this example is that while it may be true that the company that manufactured Brand X coffee was responsible for this tragic outcome, the counterargument concluding that the friend is mistaken does not bear on the issue of which coffee tastes better. This kind of relevance is also sometimes called probative relevance, where the term 'probative' refers to the capability of proving or disproving a claim at issue in a discussion or debate. In this case, the original issue is whether Brand X coffee tastes better than Brand Y or not. The claim about the product being responsible for thousands of deaths of children carries no probative weight one way or the other with respect to the claim that Brand $X$ coffee tastes better than Brand Y, or the opposed claim that Brand X coffee does not taste better than Brand Y.

It is not hard to understand the criticism that the argument against the claim in this example is not relevant. But what precisely is it about the argument that is not relevant? An answer to this question will be presented in section 6 . What is more important at this point is to understand in what sense it is not relevant.

The problem is that on the topical relevance view, the discourse topic the text segments need to "be about" corresponds to a Noun Phrase (a grammatical unit), not to a proposition expressing the purpose of the discourse or part of it (an interpretation of a discourse or a move). In this sense, topical relevance risks corresponding to the notion of local coherence, i.e. is lim- 
ited to the sentence level (Giora, 1985, p. 710).We need to distinguish at this point two concepts of relevance. A proposition $P$ is topically relevant to a proposition $Q$ if $P$ shares subject-matter (discourse topic) overlap with $Q$, considering that the topic can be either explicitly stated or underlying the whole discourse (Giora, 1985; Van Dijk, 1976; Walton, 1982). For example, $P$ is topically relevant to $Q$ if both are about oranges. The problem is that on the topical relevance view, the discourse topic the text segments need to be about corresponds to a NP, not to a proposition expressing the purpose of the discourse or part of it. In this sense, the risk of topical relevance risks corresponding to the notion of local coherence, i.e. is limited to the sentence level (Giora, 1985, p. 710).

Topical relevance, which is part of the notion of discourse coherence, is different from argumentative or probative relevance. A proposition $P$ is probatively relevant to a proposition $Q$ if there is a sequence of argumentation pro or con $Q$ that starts at or contains $P$. Probative relevance has to do with whether you can prove $Q$ by an argument containing $P$. Two text segments can be about the same explicit or underlying discourse topic (topically relevant), and coherent, but not probatively relevant. So here we have two senses of the term 'relevant' that need to be carefully distinguished.

A third sense of the term "relevant" needs to be distinguished, i.e. S\&W relevance. As mentioned in the introduction, $\mathrm{S} \& \mathrm{~W}$ relevance consists in a ratio between cognitive effects and processing efforts. Cognitive effects can be described as improvements of a person's representation of the world, namely ways in which his previous assumptions are modified. Such effects are of three types (Blakemore, 2002, p. 61):

a) Contextual implications, or assumptions that are the result of a deduction that crucially involves the synthesis of new information $P$ and the context $C$.

b) Strengthening of existing assumptions.

c) Contradicting and eliminating existing assumptions.

As a consequence, an assumption (or an utterance) will be irrelevant in a context in three cases (Blass, 1990, p. 48):

a) It is entirely unrelated to the context;

b) It is already in the context and unable to be strengthened;

c) It is inconsistent with existing assumptions, and is not strong enough to overturn them.

However, the concepts of "assumption" or "information" concern the knowledge status of the hearer, and not the weight of the conclusion nor the coherence of a text (Giora, 1997). By 


\section{Walton \& Macagno}

stating that, "Brand $\mathrm{X}$ is made by a company that also made a product that was responsible for thousands of deaths of children in undeveloped countries," the speaker is relevant to the hearer, as his statement results in cognitive effects (modifies the hearer's previous assumptions, and changes his representation of the world). This concept of relevance cannot predict in what circumstances a premise can support the conclusion, or cannot explain why a statement is probatively irrelevant, such as in the case above. While $\mathrm{S} \& \mathrm{~W}$ relevance can be useful in contexts of information sharing, in which the goal of the interlocutors is to increase the shared knowledge base, in different dialogical contexts this approach does not seem to be useful (Macagno \& Bigi, 2017a; Walton, 1989a; Walton \& Krabbe, 1995). The same problems that we pointed out with a persuasion move can be raised in dialogues in which the goal is to make a decision ("You know that I like Japanese food, why you are insisting on going to the Argentinian restaurant?"), attack the interlocutor ("You always said that you are pro-choice. But now you are saying that you are against abortion"), or negotiate ("As I told you before, I will buy the shares if you sell them at 10 dollars each"). In order to analyze the concept of probative relevance, we need to take into account first what a text segment is aimed at.

\subsection{Discourse topic, stasis, and ultimate conclusion}

The aforementioned concept of topical relevance can be developed further, taking into account the dialogue not as an interconnected set of sentences concerning the same topic or related topics, but in terms of acts aiming at pursuing a global purpose (Van Dijk, 1977). The concepts of discourse coherence and relevance need to be determined not only syntactically (and/or semantically) as connections between sentences, but also pragmatically. On this view, relevance needs to take into account the contribution of a dialogue or discourse move (Macagno \& Bigi, 2017a) to a joint communicative purpose (Van Dijk, 1977), or, better, its appropriateness to a conversational demand (Dascal, 1992, p. 45, 2003, Chapter 10; Dascal \& Katriel, 1979). On this perspective, the discourse topic to which the various discourse moves need to be relevant, becomes the problem at issue, what is problematic for the participants to the discourse or conversation (Dascal, 2003, pp. 218-219).

We can use this notion to analyze the coffee example. On this view, when analyzing or evaluating any given argument in a particular case, the first step should normally be to identify the issue, the conflict of opinions that is supposed to be resolved, which can be expressed as a proposition (or rather, conclusion). In this example, the issue is whether Brand $\mathrm{X}$ coffee tastes better 
than Brand Y. But the argument against Brand X fails to prove that the proposition that Brand $\mathrm{X}$ tasted better than Brand $\mathrm{Y}$ is false, or even subject to reasonable doubt, even though it does cast suspicion on the related proposition that it is a good idea to buy this brand of coffee. The problem is that the real conclusion of the argument attacked has been confused with another proposition, and this confusion may give the attacking argument some semblance of plausibility. This diagnosis of the problem is workable if the assumption can be made in order to properly evaluate or attack a given argument, its conclusion must first be identified. The historical genesis of this approach was the theory of stasis (sometimes called status) of Hermagoras.

According to the ancient stasis theory, generally attributed to Hermagoras of Temnos (Braet, 1999; Heath, 1994; Hohmann, 1989; Nadeau, 1959), a teacher of rhetoric in the middle of the second century BC, a speech designed to persuade an audience must be built around some ultimate proposition that is meant to be supported or attacked by the argumentation throughout the whole speech. This proposition, representing the issue to be debated by the speech is called the stasis, in Greek, or the status in Latin (Cicero, De Inventione, I, VII-VIII). Once this proposition is set in place, it determines which arguments in the speech are relevant and which are not. The standard kind of example used to illustrate how stasis theory works is that of a criminal trial (Kennedy, 1963; Pullman, 1995). When charged with theft, the defendant may deny the fact that he took the property, he may deny that the act was stealing by claiming that the property was his own, or he may admit the theft but argue that it was justified because he took a weapon from the hands of a lunatic. Such counterarguments are considered relevant in a trial because they are aimed to deny that a theft took place, or aimed to deny one of the elements of theft as they are legally defined. For example, one of the elements of the crime of theft is that the theft had to be of a property that did not belong to the defendant. Another is the proposition that the defendant meant to deprive permanently the owner of his property.

The problem posed in the coffee example appears to be easily solved by the stasis theory. The issue is whether Brand $\mathrm{X}$ coffee tastes better than Brand Y. The argument put forward is that we should not buy Brand $X$ coffee because it was made by a company that was responsible for thousands of deaths of children in undeveloped countries. On this basis, it is concluded that the claim Brand X coffee tastes better than Brand Y is mistaken. The fault in this argument is easily diagnosed. The arguer may have presented a good argument, but it was directed to the wrong claim to be proved or disputed. Of course, this analysis assumes that in everyday conversational argumentation there is 
some proposition that can be selected out in the given example as the stasis, the proposition to be proved or disputed. Descriptively speaking, this may not always be case, but normatively speaking it seems reasonable that in a persuasion dialogue of the kind the ancient writers on stasis theory were talking about, the rhetorical speaker must have some particular proposition in mind as the object of his or her persuasion attempts.

\subsection{Probative relevance and evidential weight}

As mentioned above, a move needs to be related to the ultimate conclusion of a discourse or dialogue, namely the purpose of the overall dialogue or discourse or part thereof. However, this requirement is not enough. We will analyze a second example, which seems equally simple at first, but brings in another dimension of the problem. Johnson and Blair (Johnson \& Blair, 1983, p. 87) offered an example (quoted below) that was cited as a classic case of the red herring fallacy in (Walton, 2004b).

\section{The Windsor Example}

A typical red herring was committed by then-Senator Paul Martin, well-known for extolling the virtues of his hometown of Windsor, Ontario. On this occasion, Senator Martin rose to defend Windsor against a slur contained in Arthur Hailey's novel about the U.S. auto industry, Wheels. Hailey wrote of "grimy Windsor" across the border from Detroit, "matching in ugliness the worst of its U.S. senior partner." According to press reports, Martin responded: "When I read this I was incensed ... Those of us who live there know that [Windsor] is not a grimy city. It is a city that has one of the best flower parks in Canada. It is a city of fine schools, hard-working and tolerant people".

This example can be analyzed by using the aforementioned distinction between topical and probative relevance. Thus, the proposition that Windsor is a city of fine schools, hard-working and tolerant people is topically relevant to the proposition 'Windsor is not a grimy city' because both propositions are about Windsor. But the analysis of this example by Johnson and Blair (1983, p. 87,) pinpoints the fallacy of relevance: "Fine schools and hard-working, tolerant people are no doubt an asset, but they have nothing to do with whether a city is fair or ugly". The problem is that the one proposition is not probatively relevant to the other.

The argumentation in this example can be reconstructed in the following way, beginning with the original argument put forward by Hailey and the counterargument against it put forward by Martin. The conclusion of Hailey's argument is that 
Windsor is grimy, supported by the premise that Windsor matches the ugliness of Detroit. Martin attacks the conclusion of Hailey's argument, claiming that Windsor is not a grimy city. His first premise supporting this conclusion is his statement that Windsor is a city that has one of the best flower parks in Canada. The argument seems reasonable up to this point, because having one of the best flower parks in Canada provides some evidential basis to support the claim that Windsor is not a grimy city. Then Martin goes on to add two additional premises: Windsor is a city of fine schools, and Windsor is a city of hardworking and tolerant people. The problem, as pointed out in the analysis of Johnson and Blair, is that the two additional premises are not relevant. The reason is that they do not really bear on the issue of whether or not Windsor is a grimy city. They do not provide an evidential basis to support the claim that Windsor is not a grimy city, and therefore, as pointed out by Johnson and Blair, they can be categorized as failures of relevance. We can show this reconstruction in Figure 1 below:

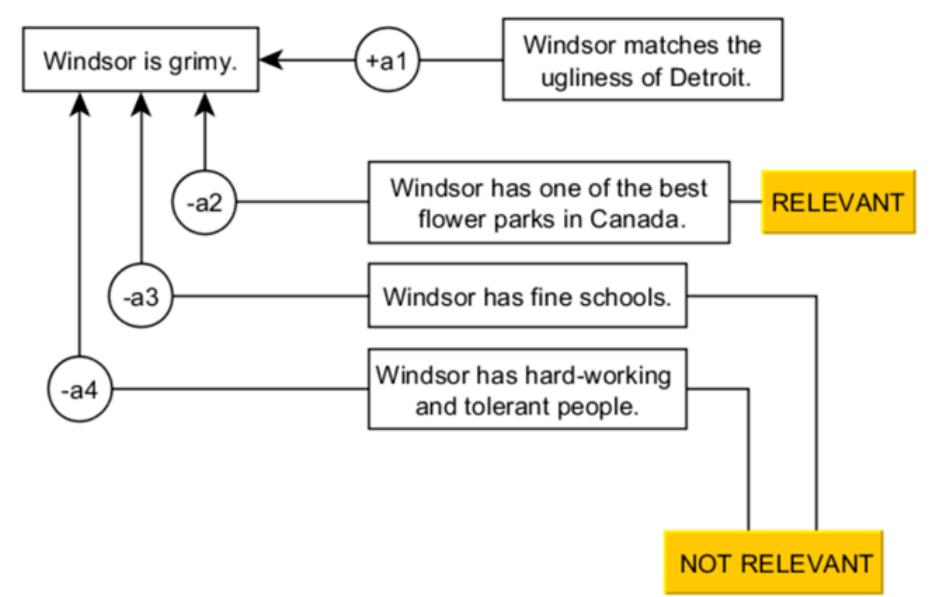

Figure 1: Cumulative Structure of the Argument in the Windsor Example

Let us take a closer look at this example to bring out an additional dimension. The argumentation in this case can be modeled as a cumulative argument. The cumulative argument is one where new premises are added to an existing argument: either these new premises give more weight to the already existing premises supporting the conclusion, or they detract from the weight of the existing premises, making the argument for the conclusion weaker than it was before.

First, we had a single premised argument stating that Windsor is a city that has one of the best flower parks in Canada. This single premised argument is relevant when put forward to attack the proposition that Windsor is a grimy city because it 


\section{Walton \& Macagno}

gives some weight of support for that conclusion. But what happens when we add in the two additional premises that Windsor is the city of fine schools and Windsor is a city of hard-working and tolerant people? Clearly, they are not relevant, because neither of them provides any additional weight to make the ultimate conclusion more acceptable than it was before. This structure is shown in Figure 1. There are four arguments, the original argument a1, and the three counterarguments a2, a3 and a4. Each of the latter three con arguments supplied is an independent basis of support for the conclusion. Hence, the general structure the argumentation fits in this case is that of a convergent argument. Pro arguments are marked with a plus sign, and con arguments are marked with a minus sign.

Notice that the argument in this case can also be classified as a cumulative argument, because these two additional premises are presumably meant to provide additional evidence to support the conclusion of the first argument. The problem is that the bottom two premises of argument 2, the con argument, do not really do that. They provide no support. As Johnson and Blair (Johnson \& Blair, 1983, p. 87) put it, the Senator did not continue building his case for Windsor's beauty. They point out that he might have continued building his case in this way, and so we might say that his failure to do so by bringing in additional premises that would make this argument stronger is a deficiency of relevance of his argument. Moreover, to the extent that there is some superficial appearance of his argument being relevant, it can be classified as an instance of the red herring fallacy. Although both premises of these two additional con arguments may be true, neither provides additional evidence to detract from the conclusion of the initial argument. In this sense, the two premises do not pursue any argumentative goal (either provide additional weight to premises or conclusion, or reduce the weight thereof).

\section{Profiles of dialogue}

Our goal in this paper is to analyze and represent probative relevance, namely the contribution of a dialogue (or discourse) move to the purpose of the dialogue or discourse, which can be represented as an ultimate conclusion (issue). This concept of relevance needs to take into account both the relatedness of the move (how a move can be about a certain conclusion) and the evidential weight it provides (how a move can make a conclusion more acceptable or defeasible). From the point of view of argumentation theory, this concept of relevance is fundamental for the purpose of analyzing informal fallacies such as red her- 
ring, ignoratio elenchi, or character attacks (Walton, 2004a). Such fallacies are committed when a dialogical move is not adequate to the dialogical context - such as in fallacious character attacks (Walton, 1989a) — or to the joint purpose of the dialogue pursued in the previous moves (or sequences) - such as in the case of irrelevant conclusion. The crucial issue is how to represent the relationship between a move and its context (where "context" is primarily conceived as the dialogue or discourse to which such a dialogue move contributes or is presumed to contribute) (Macagno, 2008; Walton, 1989a, pp. 70-71, 1998, p. 110; Walton \& Macagno, 2007).

A possible theoretical instrument that can be used for representing this type of relevance is the model of profiles of dialogue. The concept of relevance that we discussed above is strictly connected with the problem of analyzing and representing sequences of dialogue, determining and predicting the possible moves and strategies that a move can open up (Barth \& Krabbe, 1982; Hamblin, 1970, pp. 254-255; Macagno, 2011). In argumentation theory, the profile of dialogue technique (Krabbe, $1992,1999)$ was used to model sequences of dialogue and assessing the relevance thereof. Krabbe (Krabbe, 1992, p. 277) defined a profile of dialogue as a tree-shaped structure displaying the various ways a reasonable dialogue could proceed. However, this analysis was limited to some types of formal persuasion dialogues, in which one proponent and one respondent were involved with specific and clear roles. Profiles of dialogue (Krabbe 1992; van Eemeren et al. 2008; Krabbe, 1999) were used in argumentation studies to model local sequences of moves and countermoves in a dialogue to indicate how the sequence should properly proceed, according to the rules for a critical discussion. Van Eemeren (2010, p. 98) used profiles to study sequences of argumentative moves in a critical discussion to investigate argumentative strategic maneuvering. Walton (1989, pp. 37-38) applied the profiles technique to the fallacy of many questions.

Walton (Walton, 2004b) developed the profiles technique to model problematic, real cases where relevance in argumentation is a problem. Krabbe (1992) used it to analyze relevance criticisms. In these studies the profiles technique was applied to real examples where problems of relevance are posed, including questions, replies to questions, other parts of the conversation, but especially arguments (Walton, 1999). These studies recognized that there can be different standards and methods for dealing with problems of relevance in different dialogue settings where natural language is used as the medium of communication. For example, the way relevance is determined might be quite different in a court of law than in an ordinary conversa- 


\section{Walton \& Macagno}

tional setting (where no rules of procedure are explicitly formulated other than maxims of polite conversation of the Gricean type) or a forensic debate (involving a mediator).

One problem with this line of research so far is that it is difficult to bridge the gap between abstract normative models of dialogue that supposedly represent how a conversation should ideally go, and real examples where there is a problem with relevance, such as the instances of fallacies of relevance studied in logic textbooks. In this paper we have the aim of bridging this gap by defining profiles of dialogue in a special way that is meant to make it more easily applicable to such examples. Following the approach suggested by Krabbe (Krabbe, 1992) and as a development of the broader treatment of relevance in argumentation in (Macagno, 2008; Walton, 2004b; Walton \& Macagno, 2007), we will define a profile of dialogue as having a graph structure. It will be a graph structure compatible both with the technique of argument diagramming commonly found in informal logic textbooks, and with formal argumentation models from artificial intelligence.

\section{Graphs and formal argumentation systems}

A graph (Harary, 1969, p. 9) is a finite nonempty set of points along with a prescribed set of unordered pairs of distinct points (vertices, nodes). Each pair of points is a line of the graph. In a directed graph, the pairs of point are ordered. A graph is labeled when the points are distinguished from one another by means of names. A graph is usually represented as a diagram, as shown in Figure 2 below.
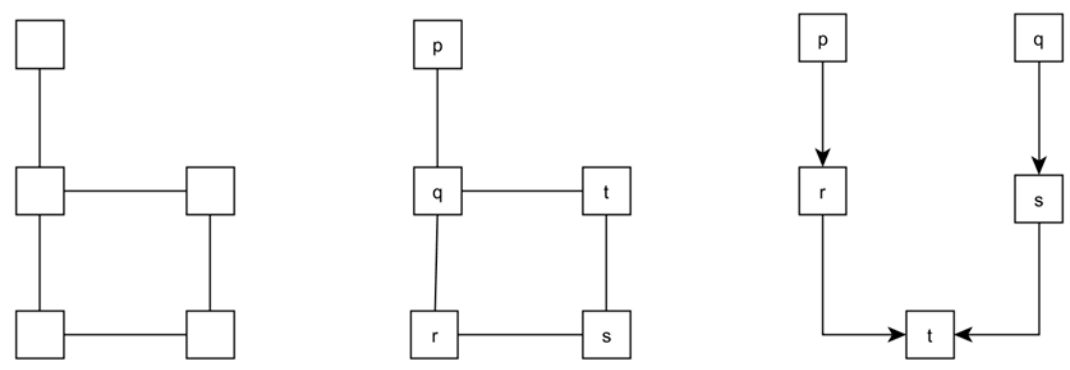

\section{Figure 2: Three Graphs}

Three graphs are shown in figure 2. The graph on the left is the only one that is not labeled. The graph on the right is the only directed graph. It is a special kind of graph called a tree, a connected acyclic graph (Harary, 1969, p. 32). A graph is acyclic if there are no circles in it. The middle graph, $(q, r, s, t)$ is an ex- 
ample of a circle. Only the third graph in figure 2 is acyclic. A path is a sequence of points and lines in which all the points (and hence all the lines) are distinct. For example, in the middle graph, the sequence $(p, q, r, s, t)$ is a path. A graph is connected if every pair of points in it are connected by a path (Harary, 1969, p. 12). All three graphs shown in figure 2 are connected. In the graph on the right, point $t$ is called the root of the tree. The graph on the right will look familiar in outline to argumentation theorists. It looks like an argument diagram of the kind often used to analyze arguments.

A bipartite graph is a graph in which the set of points nodes (nodes, vertices) is partitioned into two subsets so that that no two points in the one subset are adjacent to each other and no two points in the other subset are adjacent to each other. An example is given in figure 1, where the rectangular nodes represent propositions that are premises or conclusions of arguments while the rounded nodes (circles) represent the distinct arguments joining premises to conclusions. Figure 1 is an argument diagram in the format of the Carneades Argumentation System (CAS), a formal and computational argumentation system that helps a user to draw argument diagrams that are graphs (Gordon, 2010). CAS formalizes argument graphs as bipartite, directed, labelled graphs, consisting of two distinct kinds of points. The argument diagram is shown in figure 1 is a bipartite graph because no two rectangular nodes are adjacent to each other, and no two circular nodes are adjacent to each other. CAS enables the user to apply these graph structures to analyze and evaluate the arguments, and even to construct arguments by extending the graph using argumentation schemes along with a set of propositions in a knowledge base that is a source for implicit premises. ${ }^{1}$ Actually there are two knowledge bases it can draw on: the set of propositions representing the known circumstances of the case (including common knowledge propositions that are generally accepted), and the commitment set of the audience. The argument nodes, the circular nodes in a CAS argument diagram, are of two types, representing pro or con arguments. A pro argument supports the proposition or argument it is directed to, while a con argument attacks the proposition or argument it is directed to. Carneades argument diagrams are built by the user, although examples are available, and the diagram is displayed in a user interface that the user works with to analyse and evaluate arguments.

\footnotetext{
${ }^{1}$ Currently there are four versions of CAS (https://carneades.github.io/). The later versions are subsequent developments of the previous ones. For the argument graphs in this paper we use version 2. Version 3 models policy deliberations and version 4 models cumulative arguments.
} 
CAS also has an automated argument assistant that helps the user to find new arguments to support a claim or fill in missing premises and conclusions in a sequence of argumentation aimed at supporting or attacking an ultimate claim chosen by the user (Walton \& Gordon, 2012). As noted above, the ancient rhetoricians were known to have devised practical methods to help an arguer to search for persuasive arguments to be used in public debates by searching for arguments to support a selected proposition (Kennedy, 1963). CAS helps the user execute this task of argument invention by using the Find Arguments assistant. The user first provides an initial argument graph with the ultimate proposition to be proved or disputed, along with other premises and conclusions of the argument being analyzed. The first step the assistant takes is to perform an argument evaluation to see if the ultimate conclusion to be proved is already accepted by the audience. CAS has a commitment store containing the propositions that the audience is known to be committed to. It also has a knowledge base containing the facts of the case, propositions that are disputed by the audience, such as propositions expressing common knowledge. CAS also contains a set of argumentation schemes that are used to derive other propositions from these two knowledge bases. If it uses these resources to find one or more sequences of argumentation that reach this end point, and therefore are provably relevant, it gives this information to the user and shows the sequences that lead to this conclusion. If it fails to find such a path, the assistant tells the user and fills gaps by searching for and finding possibly incomplete but useful sequences of argumentation arguments by drawing further on premises found in the commitment store of the audience. By expanding the original argument graph in this way it helps the user to build a mass of evidence that can be used to evaluate how relevant the original argument is as a way of proving or attacking the ultimate conclusion.

Next we introduce an extension of the profiles method (Walton, 2015) that works to evaluate problem cases by using a pair of graphs, and by comparing the one graph to the other. The one graph, called the descriptive graph, is the initial graph that would be drawn up by the analyst to represent a more or less descriptive but incomplete representation of the argumentation in the natural language discourse in a given case. This graph will have some normative components but by its nature is intended to be more descriptive than the other type of graph, called a normative graph. The normative graph represents how the sequence of argumentation represented in the descriptive graph ideally should have proceeded. It is based on the initial graph but it is more normative in nature because it is supposed to bring out some aspects missing in the original graph but necessary to 
judge features such as relevance. The normative graph is mapped into the descriptive graph so that a comparison can be made to determine what is missing or otherwise problematic in the sequence displayed by the descriptive graph.

The third part of the procedure goes the other way. The argument analyst compares the two graphs to examine and analyze what was missing in the descriptive graph. By this means the analyst is able to explain the problem that was displayed visually by the information in the descriptive graph, and by means of moving to the normative graph, diagnose the nature of the problem and build a recommendation on how to fix it. The intent of using the profiles method is to not merely identify a problem, for example by associating it with some kind of traditional informal fallacy, but also by going beyond that to examine the nature of the failure to find a way of repairing the fault. So conceived, the profiles method can be described as a fault diagnosis tool that can be applied to real examples of problematic argumentation in everyday discourse in natural language to show how the fault, once it has been identified, can be fixed (Walton, 2015). Finding a problem or apparent fault in a case of perceived irrelevance can be very important. But as will be shown in an example below, proving that an argument or claim is irrelevant can be much harder.

Once the argument analyst has constructed a descriptive graph representing an interpretation that is supposed to be faithful to the original text, a formal argumentation system such as CAS can be applied. ${ }^{2}$ However, the profiles method is not dependent on any particular formal or computational argumentation system for some of its practical uses. Someone who wants to collect evidence to support an evaluation of the relevance or irrelevance of an argumentative move in a given example of natural language discourse can apply the profiles method by using a pencil and paper. The first step is to draw a rough sketch of a descriptive graph representing the explicit features of the argumentation presented in the text. The second step is to draw another rough sketch of a normative graph that fills in gaps in the first graph representing hypothetical paths leading from the premises and conclusions pictured in the first graph to the ultimate conclusion that is supposed to be proved in the case, as far as that is known. The third step is to compare the two graphs to identify gaps or problematic parts of the first graph. ${ }^{3}$ We began

\footnotetext{
${ }^{2}$ Especially because CAS has a Find Arguments assistant, it can offer the user helpful information about potential paths to proving the ultimate conclusion as identified by the user in the initial graph.

${ }^{3}$ This procedure can be carried out manually, even though simple argument diagramming (mapping) tools can be very helpful. Argument mapping tools such as Araucaria, Rationale, and so forth, are widely available (Scheuer,
} 


\section{Walton \& Macagno}

with two examples of relevance that seemed to be relatively easy to deal with. We will now turn to two more examples that are much more challenging.

\section{The bank robbery example}

The following dialogue is quoted below with minor typographical changes from (Mauet, 2005, p. 533), a book designed to teach argumentation skills for use in legal trials. This particular dialogue is used to illustrate the evidential objection of irrelevance. This particular example is meant to represent a typical case where one of the lawyers makes an objection, on grounds of relevance, to evidence put forward by the other side.

\section{The Bank Robbery Example}

Prosecutor: Mrs. Higgins, were you at the bank on June 1, one week before the robbery?

Mrs. Higgins: yes.

Prosecutor: Did you see the defendant that day?

Defense lawyer: Your Honor, we object on relevance grounds. May we approach?

Judge: Yes [Lawyers come to the bench.] Prosecution, where's this testimony going?

Prosecutor: the witness will testify that she saw the defendant outside the bank that day, that he was looking at the bank, but never came inside.

Judge: What does that prove?

Prosecutor: It shows that the defendant was already planning the robbery and casing the bank.

Defense lawyer: the fact that he was outside the bank hardly proves he was planning to rob it.

Judge: The objection is overruled. The witness may answer.

To put the example in context, the book explains the legal definition of relevance stated in Rule FRE 401 in the Federal Rules of Evidence, a set of criteria that is applicable in many jurisdictions in the United States. FRE 401, in Article IV, entitled Relevance and its Limits, states the following test for relevant evidence: "Evidence is relevant if: (a) it has any tendency to make a fact more or less probable than it would be without the evidence; and (b) the fact is of consequence in determining the action." Part (b) of the test is that the evidence must be of consequence to the action. The so-called action is the ultimate propo-

Loll, Pinkwart, \& McLaren, 2010), easy to use, are often free, and can be used to make and store argument diagrams. Other software drawing tools such as Microsoft Visio and GraphML are also useful to draw graphs of the kind illustrated in the following examples. 
sition to be proved or brought into question. In a criminal case this will be a plea that the defendant committed some crime, and this claim has to be proved by the prosecution to the standard of beyond reasonable doubt. The judge has to explain these matters to the jury. The ultimate claim to be proved is composed of what are called elements. For example in a murder trial, the two elements would be that the defendant killed the victim and did so with a guilty mind. In other words the elements are the required findings to prove the ultimate claim, and so an argument purporting to provide evidence to prove the ultimate claim must have a claim, or one of the elements of it, as its conclusion.

To put the point very simply, a chain of argumentation claimed to be relevant can only pass this second test of relevance if it aims at its final stages at proving or attacking the ultimate claim or one of its elements. Part (a) concerns what is often called the probative weight of the evidence. This test of relevance is that the argument put forward must be probative, so that it has at least some tendency to prove or disprove the ultimate claim or one of the elements. It doesn't have to be a conclusive argument for the ultimate conclusion. It only has to carry enough probative weight to make it able to go along with other evidence that can prove the ultimate conclusion to the required standard of proof. This test is required because some kinds of arguments, such as a character attack, can be slightly relevant, but can still be dismissed as irrelevant for the reason that they might tend to prejudice the jury. In other words, the argument must have enough probative weight so that it cannot be discounted as irrelevant.

Notice particularly in this dialogue, the judge asks two questions to the prosecuting attorney concerning relevance. First he asks where this testimony is going, and later he asks the question "what does that prove?" Both these questions are shown in Figure 3. The statement shown at the bottom right in the rectangle with the dashed border is an implicit premise.

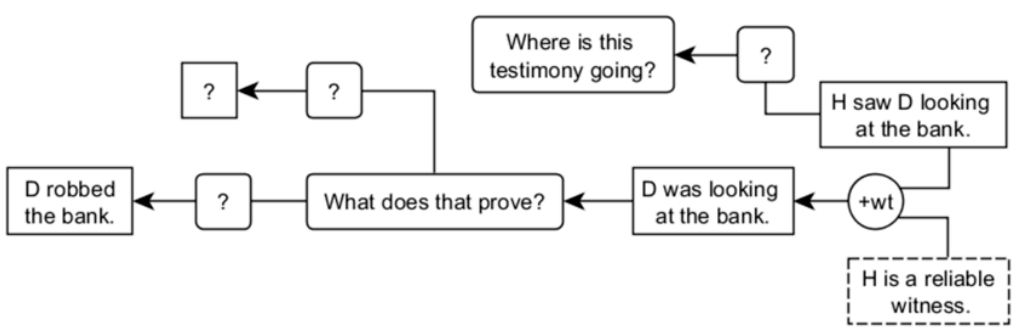

Figure 3: Questioning Relevance in the Bank Robbery Example

The ultimate conclusion to be proved, the claim that D robbed the bank, is shown in the rectangular node at the left of the diagram. The statement that $\mathrm{H}$ saw $\mathrm{D}$ looking at the bank is shown as a premise of the argument from witness testimony 
shown at the right. The two questions concerning relevance asked by the judge are shown in the two rectangular nodes with rounded corners. When the prosecutor first introduced the evidence about Mrs. Higgins seeing the defendant at the bank on the day before the robbery, the defense lawyer objected on grounds of relevance, and the judge asked where this testimony is going. At that point there was no information from the prosecutor on where this testimony was going. There was a large gap between the witness testimony about the defendant being at the bank that day, and the ultimate conclusion that the defendant robbed the bank the next day. True, he was in the vicinity of the bank that day, but so were lots of other people, and this statement by itself does too weak as providing any evidence to support the ultimate conclusion with any strength.

Next in the dialogue the prosecutor brings in the argument from witness testimony showing that the defendant was looking at the bank, but never came inside. The latter assertion, that the defendant never came inside, sounds slightly suspicious, because it removes the possibility that the defendant might have some other reason for being in the vicinity of the bank, such as making a transaction in the bank. But let's just disregard this part of the argument for the present. At this point in the sequence of argumentation, the judge once again questions relevance by asking "What does that prove?" The two question marks shown in the rounded rectangle nodes at the left of figure 1 visually represent the implications of this question. Does the evidence of the witness testimony produce a sequence of argument that leads to the proving of the ultimate claim? Or does it go off somewhere else veering away on a tangent in some other direction, perhaps arriving at some other conclusion unrelated to the one that is supposed to be proved? These question marks represent gaps in the argument that pose a problem because they reveal the missing parts in the sequence of argumentation needed to get from the initial argument from witness testimony to the ultimate conclusion to be proved.

\section{The tuna fish example}

The following example comes from a debate in the Canadian House of Commons where the question for discussion was whether or not to make amendments to a bill called the Family Allowances Act. The specific question was whether a proposal for increasing government benefits paid to support families through this bill should be accepted or not. As the debate continued, surprisingly, one Member of Parliament (MP) who was against the amendments, made a lengthy attack on the govern- 
ment on a range of charges, including the charge that the government had refused to take a million cans of tuna off the shelves that should not have passed inspection. Recently there had been attacks on the government concerning the so-called "tuna scandal" in which it was alleged that government officials failed to apply health standards to block the sale of cans of substandard tuna fish from being made available in supermarkets.

The Acting Speaker of the House tried to restrain the MP by questioning the relevance of these remarks on the tuna scandal to the debate on the Family Allowances Act. The Speaker's objection and the MP's answer are quoted below from (Walton, 1989b, pp. 205-207).

\section{The Tuna Fish Example}

Speaker: order, please. The Hon. Member knows that we are debating the amendment to the Bill on family allowances. I do not know why we are debating tuna fish. I hope the Hon. Member will get back on track.

MP: Mr. Speaker, my reference to tuna relates to the health and welfare of Canadians, which is also being dealt a fatal blow as a result of this particular legislation on family allowances.

What is interesting in this example is that the MP makes an attempt to connect the tuna fish scandal to the motion to amend the Family Allowances Act, by following up with the argument quoted below from (Walton, 1989b, p. 206).

MP: With regard to the main question, which is family allowances, we are talking about the people who would be most affected by this cutback. The government says that $\$ 22$ is not a lot for Canadian families. Well, families and single parents who are struggling to raise small children, often surviving on tuna, are being directly assaulted by the government's anti-family budget measures [our italics].

These remarks make it clear make it clear that the MP is arguing against the amendments to the bill, but something else is going on as well. The expression "often surviving on tuna" makes it evident that the MP is trying to make a link between the amendment that is the issue to be decided and the tuna scandal. The problems are (1) what kind of link this is supposed to be, and (2) whether it is strong enough to support the claim that the MP's bringing in the tuna scandal is relevant to the proposal to amend the Family Allowances Act.

The debates in the Canadian House of Commons have a format comparable to that of the British system of parliamentary debates, including a Question Period in which members can put questions to a representative of the governing party. These de- 


\section{Walton \& Macagno}

bates are televised, and a record is kept of them. In the Canadian system, the record of the debates is called Hansard. One member, designated as the Speaker, acts as moderator, to see that the rules of debate, as set down in the parliamentary debate rulebook, are followed. There is a rule of relevance, but applying it is left up to the judgment of the Speaker. ${ }^{4}$ Under the heading Rules of Order and Decorum, the rule regarding relevance is aimed at excluding any discussion from a debate which does not contribute to the debate by preventing an MP from "straying from the question being debated in the House". However it is noted that the rule of relevance is "somewhat difficult to define and enforce". The reason given is that it is not always possible to judge the relevance of an MP's remarks until he or she has completed them, or at least made some progress. If the Speaker does not allow enough latitude, debate could be "severely curtailed" but if too much latitude is allowed there can be a loss of time, preventing other MPs from participating in the debate. The Speaker can warn an MP to desist, and if he or she ignores the warning he can "direct" the MP to stop speaking so that someone else can speak.

In this instance, the Speaker intervened into a lengthy speech by saying that the participants are supposed to be debating some particular amendments to a bill on family allowances. Here we do not go into the details of the bill itself, or the specific amendments that have been proposed and are to be voted on. It is enough to know that they represented financial matters of government benefits that involve money paid out to families that qualify for assistance. In the part quoted, the Speaker begins by reminding the participants that they are supposed to be debating these specific proposed amendments and says "I do not know why we are debating tuna fish", using the expression getting "back on track". These remarks raise the question of how the member's extensive argumentation on the tuna fish issue is relevant or not to this debate on the amendments. The Speaker's objection on grounds of relevance puts a question to the member as shown in Figure 4.

\footnotetext{
${ }^{4}$ The primary procedural authority for the rules for parliamentary debate in the Canadian House of Commons is the House of Commons Procedure and Practice. The 2000 edition, edited by Robert Marleau and Camille Montpetit, can be found on the Internet here at this site: http://www.parl.gc.ca/marleaumontpetit/DocumentViewer.aspx?Sec $=$ Ch13\& $\underline{\text { Seq }=4 \& \text { Language }=E}$ (Accessed on 16 November 2016).
} 


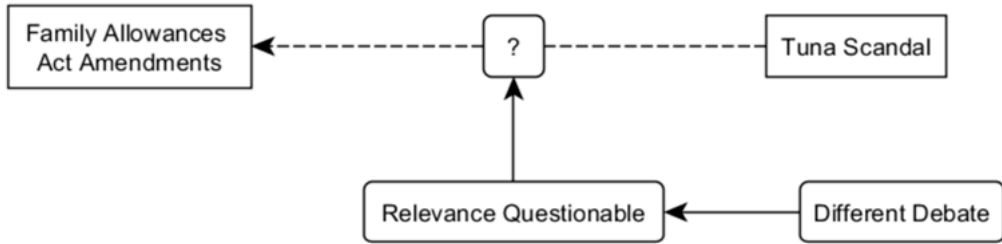

Figure 4: First Step in the Tuna Fish Example

The Speaker is asking what the connection is between the MP's previous argumentation on the tuna scandal and the amendments to the Family Allowances Act that is currently the subject of the debate. At this point the Speaker is not claiming that the previous argumentation about the tuna fish issue is irrelevant. He is merely raising the question by asking the MP to show how it is relevant. He is stating that from the point of view of relevance, the one is a different debate from the other, and so is asking the question of how the two are connected.

The MP's first response replies to this question by stating that both issues relate to the health and welfare of Canadians. This assertion is true, in the sense that the two issues are topically relevant to each other in the sense that they have the common subject matter 'health and welfare of Canadians'. But overlapping subject-matter is not enough to establish probative relevance, which can only be proved by showing a sequence of argumentation connecting the MP's conclusion about the Family Allowances Act to some evidence based on tuna fish. But perhaps there is some evidence that such a sequence can be reconstructed.

The MP also states that this particular legislation on family allowances, presumably referring to the Family Allowances Act, is having negative consequences with respect to the health and welfare of Canadians. This part of the argument is shown in Figure 5, which makes an attempt to trace out some sort of connection between the two issues based on the common element of the health and welfare of Canadians.

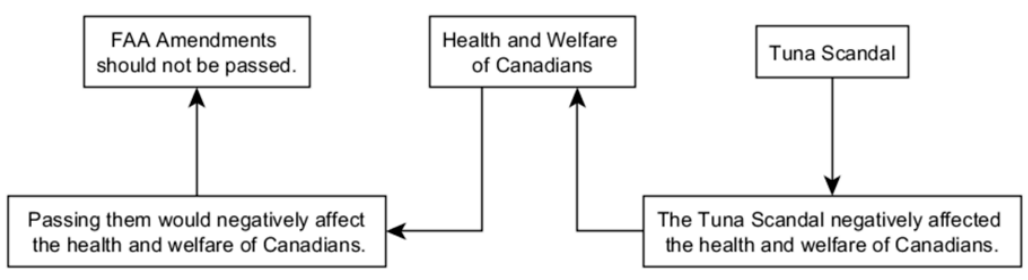

Figure 5: Second Step in the Tuna Fish Example 


\section{Walton \& Macagno}

It is somewhat speculative to try to draw out this connection as a clearly defined sequence of argumentation, but the sequence outlined in figure 5 represents a hypothesis connecting the dots. The MP's argumentation attacking the government on the subject of the tuna scandal was about how the action by the government of allowing the supposedly unsafe cans of tuna to be distributed to the public negatively affected the health and welfare of Canadians. So this argumentation was connected with the health and welfare of Canadians. But this latter issue was also connected to the FAA amendments being discussed, because it is being argued by the MP that passing these amendments would negatively affect the health and welfare of Canadians. Nevertheless, this claim that there is some sort of connection between the tuna scandal and the amendments being considered is still very sketchy. The question is whether enough gaps can be filled in so that the whole can be reconstructed as a sequence of argumentation.

In the next set of remarks quoted above, the MP makes the correction by stating that these negative consequences have come about because families and single parents who are struggling to raise small children, often surviving on tuna, are being negatively affected by the proposed amendments to the family allowances act. Here then is the connection being made to support the claim of relevance, namely the statement that these families and single parents struggling to raise small children are often surviving on tuna. No evidence at all is given for this claim by presenting any statistics representing the number of families and single parents struggling to raise small children often surviving on tuna. Nevertheless, a link has been made between the two issues.

\section{Applying the profiles method to the coffee example}

The reader will recall that in the coffee example the argument against Brand $\mathrm{X}$ (which we will refer to as $A$ ) was that "the friend who said that Brand $\mathrm{X}$ coffee tastes better than Brand $\mathrm{Y}$ was ignoring the fact that the company making Brand $\mathrm{X}$ made a product that was responsible for thousands of deaths of children". What is the argument here? The issue is which brand of coffee tastes better Brand X or Y? A descriptive account of what is actually happening in the example is the following: the friend's saying that Brand $\mathrm{X}$ tastes better than Brand $\mathrm{Y}$ is put forward as an argument supporting the claim that $X$ tastes better. But then this argument is attacked by the counterargument that the friend was ignoring the fact that the company making Brand 
$\mathrm{X}$ made a product that was responsible for thousands of deaths of children.

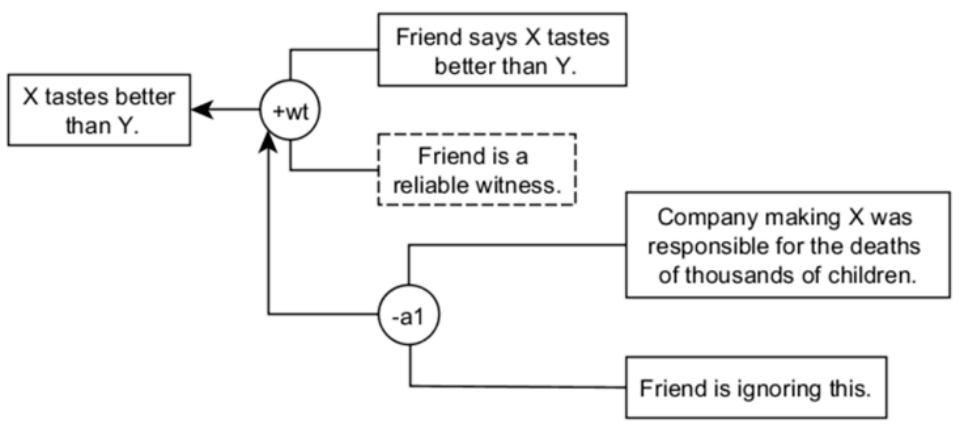

Figure 6: Descriptive Graph for the Coffee Example

When the argument is configured this way, as shown in figure 6 , it looks like it is an attack on the prior argument from witness testimony, indicated by the scheme for argument from witness testimony $w t$. Because of the negative consequences of deaths of thousands of children in underdeveloped countries, the argument may seem somehow relevant. But as shown in the reconstruction in Figure 6, this argument carries no probative weight as an attack on argument wt. Even though the premises of argument a1 may be accepted, they do not offer a good reason to reject the argument from witness testimony. The reader will recall however that what is needed to solve the problem in the coffee example is to see that it ignores the first step of properly identifying the conclusion of the sequence of argumentation in the given case. The conclusion stated in the text given for the example is the statement that Brand $\mathrm{X}$ coffee tastes better than Brand Y. But as shown by the reconstruction of the arguments in figure 6 , this argument al fails to prove that the conclusion is false, or even gives a reason for doubting it. The diagram shows how the relationship between the conclusion and the critical move requires further steps (a friend ignoring the company's responsibility cannot be trusted relative to the knowledge of the company; a friend that cannot be trusted relative to knowledge of the company cannot be trusted in terms of taste; if a friend cannot be trusted his argument should not be given so much weight). Such steps are each defeasible, as they conflict with the hearer's accepted or acceptable premises (McGuire, 1960, 1966), namely with his existing assumptions (Petty \& Cacioppo, 1986, p. 68; Petty, Rucker, Bizer, \& Cacioppo, 2004, p. 127). In this sense, $A$ is less likely to be acceptable (Lewis, 1979), failing to strengthen or contradict the conclusion.

The problem is that the real conclusion of the argument that has been attacked is the proposition that it is a good idea to 
buy Brand X coffee. Supplying this information, the argument can be alternatively reconstructed as shown in Figure 7. According to this way of reconstructing the example, the ultimate conclusion shown at the far left is the proposition that it is a good idea to buy X. Argument from witness testimony concluding that $\mathrm{X}$ tastes better than $\mathrm{Y}$ is shown as a pro-argument supporting the conclusion that it is a good idea to buy $\mathrm{X}$.

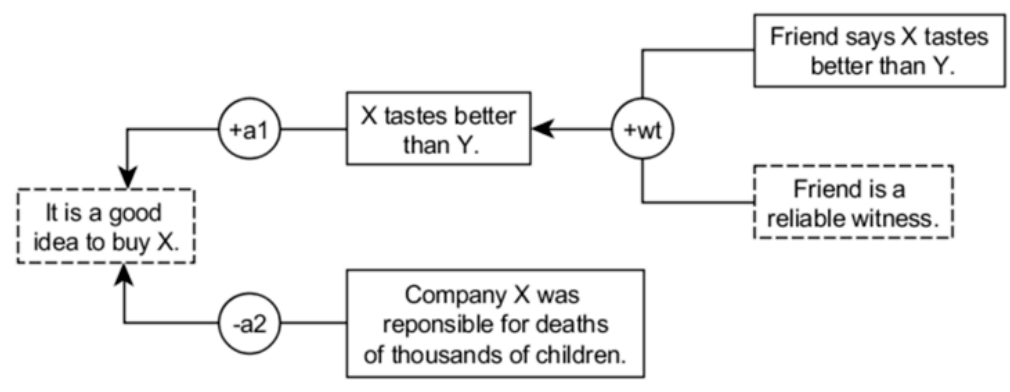

Figure 7: Normative Graph for the Coffee Example

But there is also a con argument shown at the bottom. The proposition that company $\mathrm{X}$ was responsible for deaths of thousands of children is shown as a reason for not accepting the conclusion that it is a good idea to buy X. This argument is much more reasonable as offering support for its ultimate conclusion, but it also reveals the failure of relevance of the original argument, by configuring the argument in such a way that the real conclusion should be the proposition that it is a good idea to buy $\mathrm{X}$.

When interpreted normatively the argument is an instance of value-based practical reasoning that needs to be judged by standards of practical rationality. By these standards, it is a procon argument about what course of action to take, to buy Brand $\mathrm{X}$ coffee or Brand $\mathrm{Y}$. The arguments pro and con the course of action of buying Brand $X$ are shown in Figure 7. It is relevant when judged as part of a deliberation on the issue of which brand of coffee to buy. When interpreted descriptively however, as shown in Figure 6, the issue is which brand of coffee tastes better. Here the issue is a conflict of opinions which needs to be settled in a framework where pro and con arguments are also brought forward to prove or refute a central claim. The problem of relevance in this difference about the ultimate conclusion to prove is matter of dialogical ambiguity, namely the interpretation of the joint goal of the conversation (Macagno, 2011; Macagno \& Bigi, 2017a, 2017b). The descriptive interpretation of the argument shown in Figure 6 can rightly be criticized as representing an instance of the red herring fallacy, essentially 
because the argument has been directed to the wrong conclusion.

These two argument diagrams when compared to each other provide the tools needed to implement the profiles of dialogue method as applied to this example. Figure 7 shows how the previous faulty argument can be reconstructed in a manner to make it more reasonable by showing how the real conclusion of the argument has been confused with another proposition where this confusion gives the attacking argument some semblance of plausibility.

\section{Applying the profiles method to the Windsor example}

To begin with, the problem in the Windsor example seems similar to the problem discussed above about the coffee example. The fallacy consists in the superficially apparent irrelevance of these latter two propositions. They are both about the city of Windsor. Hence they are topically relevant, meaning that they share subject-matter with the issue being discussed. But they are not probatively relevant, because they do not offer evidence to support or refute the conclusion that Windsor is a grimy city. The first part of the argument is relevant because when it is stated that Windsor has one of the best flower parks in Canada, this is a relevant counterargument to the ultimate conclusion at issue, the proposition that Windsor is grimy. So far so good, but then when the other propositions are introduced, the one stating that Windsor has fine schools and the other stating that Windsor has hard-working people, these are not relevant, because they cast no doubt on the claim that Windsor is grimy (or the claim that it is not).

But there is an additional component to this example. The first counterargument is relevant, but the remaining two are not. The argument started out by being relevant, but then wandered away on to other issues that have no apparent probative relationship to the stasis. For example it looks like there is no way to get from the premise that Windsor has fine schools to the conclusion that Windsor is not grimy. The problem is that there is no argumentation link between these two propositions. Maybe the gap could be filled in by further argumentation that somehow links up fine schools with not being grimy, but it is hard to see how this could be done, and it looks prima facie plausible on the surface that it cannot be done.

The problem of relevance illustrated by this example can be modeled by applying the profiles method. The initial step has already been shown in figure 1. As the argumentation stands, argument a 2 seems to be relevant, whereas arguments a3 and a4 


\section{Walton \& Macagno}

do not. But how could these appearances be modeled using another argument graph that represents the underlying structure showing how all the argumentation should be modeled normatively? What has to be done is to take each of the three arguments in question and try to extrapolate them forward so that they are probatively relevant to the conclusion, the statement that Windsor is grimy. But if we were to use the Find Arguments assistant in CAS to input each of these premises, none of them would find a path to proving the ultimate conclusion Windsor is grimy.

CAS has a knowledge base including propositions representing the known circumstances of the case and also containing some generalizations based on common knowledge. Let's take it to be a generalization based on common knowledge to the effect that if a city has one of the best flower parks in Canada this can be taken as a defeasible reason going against the claim that the city is grimy. We will also assume that this knowledge base contains the common knowledge propositions that Windsor and Detroit are cities. Given these needed implicit background assumptions, we can construct a path that moves forward from premises to the ultimate conclusion that is supposed to be proved in the case.

This is easily done with arguments a1 and a2. An implicit premise can be added to al stating that Detroit is an ugly city. This was widely accepted at the time, even though it is now changing. An implicit premise can be added to a2 to the effect that if a city has one of the best flower parks in Canada, that is an argument, not a conclusive one but a defeasible one, that casts doubt on the conclusion that Windsor is grimy.

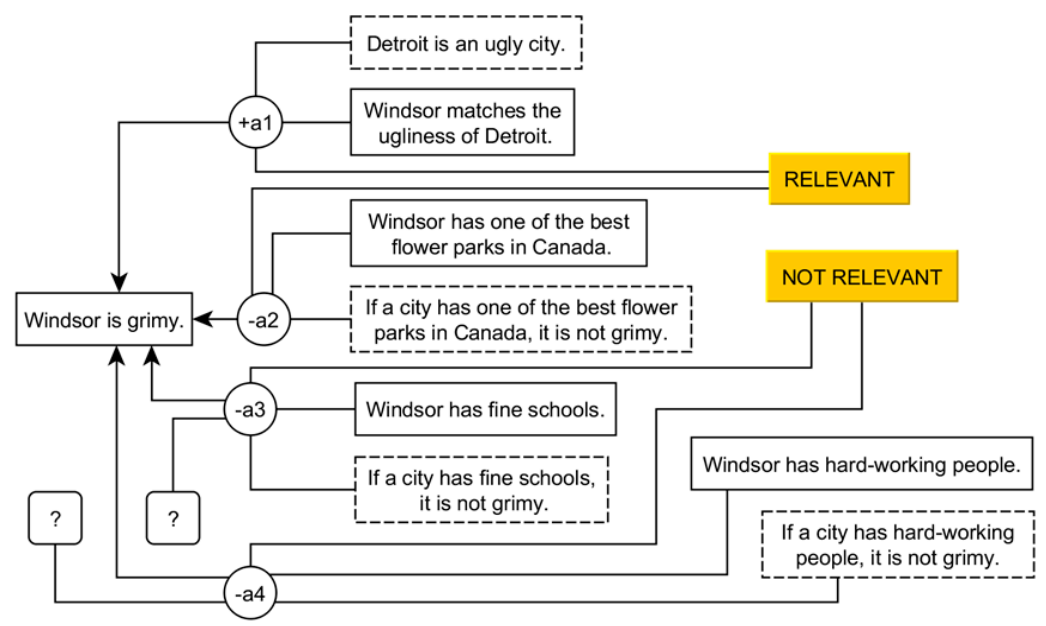

Figure 8: Step 2 in the Windsor Example 
On this reconstruction we can chain the first argument forward so that it is relevant to this conclusion. But it does not work for the other two arguments a3 and a4. An argument graph displaying the second step needed to complete the profile of dialogue is shown in figure 8.

This example also illustrates the concept of conditional relevance. $P$ is conditionally relevant to $Q$ where the derivation of $Q$ from the premise $P$ depends on an additional implicit premise $R$. This definition of conditional relevance requires (1) that $Q$ cannot be derived from $P$ alone, without the additional assumption $R$, and (2) that $Q$ can be derived from $P$ and $R$ once $P$ and $R$ form a linked argument with $Q$ as its conclusion. A linked argument as defined in informal logic, is one where two or more premises work together to support a conclusion, so that these premises depend on each other. The problem of relevance revealed in the profile of dialogue shown in figure 8 is that the two implicit premises shown at the bottom, needed to support arguments a 3 and $\mathrm{a} 4$ are both false. The important point demonstrated here is that relevance of an argument can be negated by a false premise in it.

The two question marks in figure 8 represent the question 'Where is this line of argumentation going?' The problem is that it does not appear that it can go anywhere without being based on the two implicit premises in the rectangles at the bottom shown with dashed borders. Arguments a3 and a4 do not appear to be useful to establish relevance because in both instances the needed implicit premise is not found in the common knowledge database. Both generalizations needed to make the obvious path to the ultimate conclusion fail. This normative reconstruction presents a graph that shows what is needed to pass the test of probative relevance, and shows why the first two arguments are relevant while the other two are not.

The objections on grounds of relevance indicated in this graphical representation of the argumentation in the Windsor example should not be taken to represent conclusive refutations of the two arguments they point to. They merely raise questions about where the argument is supposed to be going. The asking of such a question shifts an evidential burden to the other party in the dialogue to give some indication of why the argument should be considered relevant. If the other party gives no response at all, there is a default (ceteris paribus) to the assumption that the argument is not relevant. By this means, a burden of proof is placed on the defender of the argument to offer some evidence that can be used to sketch out a sequence of argumentation leading from the questioned proposition to the ultimate conclusion. 


\section{The profiles method in the bank robbery example}

The prosecutor's answer to the judge's question about what the evidence so far proves fills in these gaps by revealing the sequence of argumentation in the prosecutor's strategy. The sequence of argumentation is shown in Figure 9, which is a standard argument diagram modeled according to the requirements of version 2 of CAS.

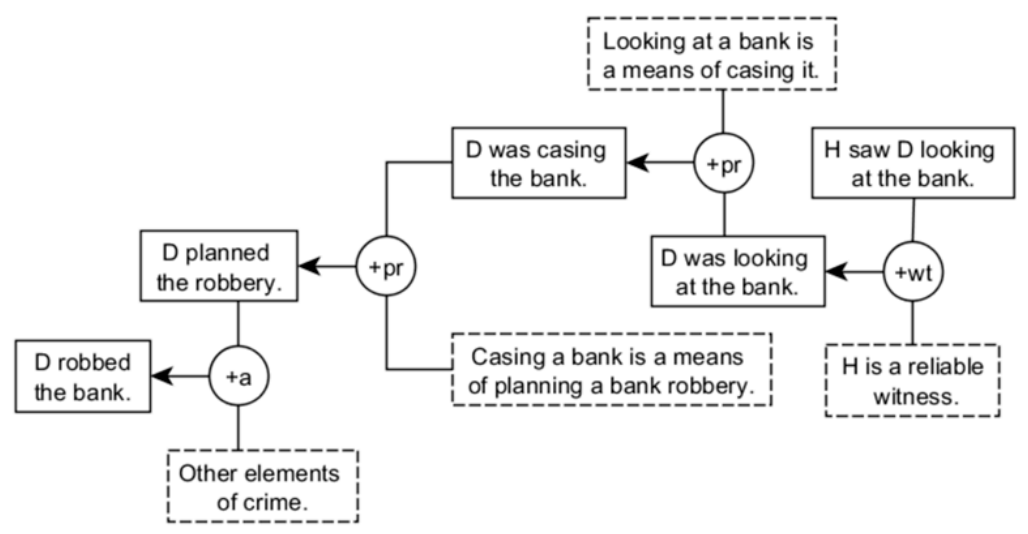

Figure 9: Showing Relevance in the Bank Robbery Example

In this diagram, the statements in the rectangular nodes where the rectangles are shown with broken lines as perimeters, represent implicit premises that would be acceptable to the audience, based on its commitment store and common knowledge. The notation $+p r$ refers to the argumentation scheme for practical reasoning, the plus sign indicating a pro argument. Figure 9 displays the sequence of argumentation connecting the initial argument from witness testimony to the ultimate conclusion that the defendant robbed the bank. The first step is the argument from practical reasoning based on the implicit premise that looking at a bank is a means of casing it. This argument leads to the conclusion that the defendant was casing the bank, which in turn is used in another argument from practical reasoning to support the conclusion that the defendant planned the robbery. Depending on how robbery or theft is defined in a particular jurisdiction, this crime will have several elements, such as statements to the effect that the defendant intended to take money from the bank, did not intend to return it, and so forth.

By means of the structure modeled in figure 9, once you look over this argument diagram, the questions of where the line of argumentation is going has been answered. The missing parts represented by the question marks in figure 4 have been filled in. So now we have an answer that the prosecutor could give to 
the questions of the judge and the defense lawyer expressing doubts about the relevance of the witness testimony in the trial.

\section{The profiles method in the tuna fish example}

The MP's move by stating that Canadian families were often struggling to raise small children often surviving on tuna fish did form a link between the debate on the amendments to the Family Allowances Act and tuna fish scandal. But reconstructing the link as a connected sequence of argumentation using the profiles method is a difficult and convoluted conjectural task.

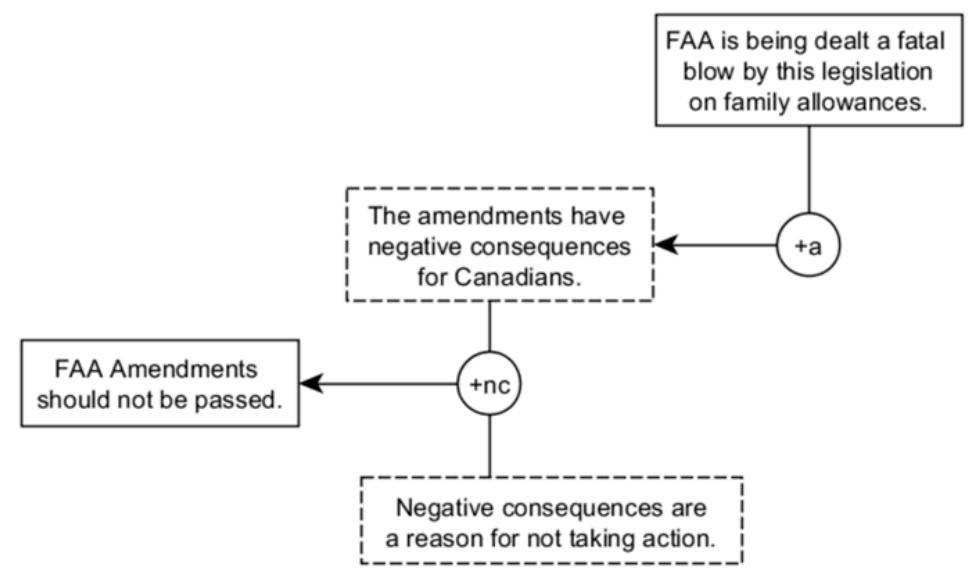

Figure 10: Third Step in the Tuna Fish Example

In this section we with carry this task further by starting from both ends to work toward the middle. To carry out this task we have to fill in some implicit premises, as represented in Figure 10. An implicit premise is one that has not been explicitly stated, but that is necessary to insert as an assumption in order for the sequence of argumentation to fit argumentation schemes and otherwise to move ahead as a sequence of argumentation that makes sense as a provisional interpretation of what an arguer might be trying to say.

The MP uses emotive language in the expression "being dealt a fatal blow as a result of this particular legislation" and the expression "directly assaulted by the government's antifamily budget measures". Emotive language contains powerfully emotive sentiments that can be either positive or negative in influencing an audience through indirect and unstated implicatures (Macagno \& Walton, 2014). To extract an argument from the text in this case, we assume that it is being implied that the amendments have negative consequences for Canadians and that these negative consequences are a reason for not taking action to 


\section{Walton \& Macagno}

pass the amendments. So interpreted, this part of the sequence of argumentation is shown in figure 10.

Now we have the problem of trying to figure out how the sequence of argumentation shown in figure 10 could be connected to the sequence shown in figure 6 in such a manner that relevance is shown between the argument about the family surviving on tuna fish shown at the right side of figure 6 and the ultimate conclusion of this whole line of argument. In other words, how does the story about families struggling on a diet of tuna fish relate to the sequence of argumentation to the MP's ultimate conclusion that the amendments to the Family Allowances Act should not be passed? As with any attempt to apply an abstract model of rational argumentation to a real instance of the sequence of argumentation on a contested issue expressed in natural language discourse, the reconstruction has to be regarded as a hypothesis, a defensible explanation of what was said based on the textual evidence.

The sequence of argumentation shown in figure 10 has its final conclusion at the left, the statement that the family act amendments should not be passed. The problem now is to try to figure out how the remarks about families struggling to raise small children on tuna fish are connected to this previous part of the argumentation. To do this, we reconstruct the previous part of the argumentation using the graph shown in Figure 11.

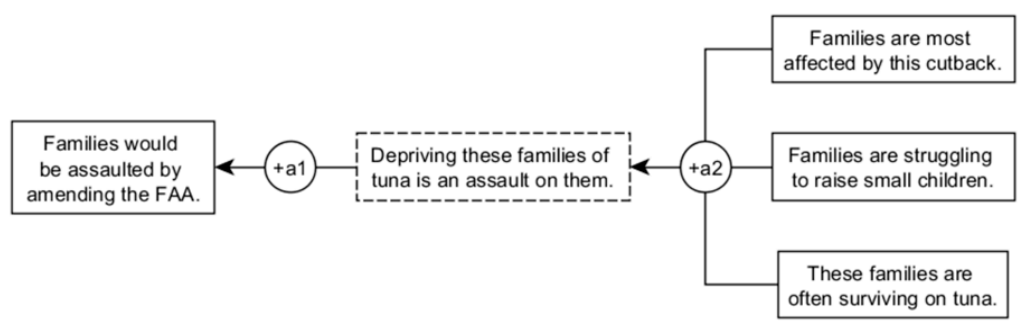

Figure 11: Fourth Step in the Tuna Fish Example

Looking at figure 11, we can see on the right that there is a pro argument with three premises incorporating the information that families most affected by the amendments to the bill are struggling to raise small children often surviving on tuna. This argument somehow gets us to the conclusion shown at the left stating that families would be assaulted by amending the family allowances act. How is it possible to get from the one point to the other representing the argumentation as some kind of sequence of reasoning? It can be done by interposing the conclusion that depriving these families of tuna is an assault on them, as shown in the reconstruction of the argument in figure 11. 
The poor relevance of this example is brought to light by the diagram, which shows two critical points of the argument. On the one hand, the premise requires additional steps that need to be reconstructed, resulting in high processing efforts (Blakemore, 2002; Wilson \& Sperber, 2004). On the other hand, the cognitive effects (in this case supporting the intended conclusion) are weak, due to controversial implicit premises that can provide little support to the claim. The especially weak link in this chain of argumentation is the use of the premise that these families are often surviving on tuna. It is possible that this proposition was true at the time, but no evidence was given to support it, and it does seem more than a little dubious. It looks suspiciously like something that has been thrown in to reply to the Speaker's questioning of the relevance of the tuna fish scandal in the debate on the amendments to the Family Allowances Act. The Speaker did not question this statement, or ask the MP to prove it, but simply went on to recognize the next MP who wanted to speak.

\section{Conclusions}

This paper provides an approach to relevance defined in terms of argumentative steps needed to reach an intended conclusion in a discourse or dialogue. Relevance is regarded from a twofold perspective. On the one hand, it is represented in terms of argumentative relations between an argument (and more generally a dialogue move) and the joint communicative purpose (the topic or the possible conclusion that can pursue a common dialogical goal), which is represented propositionally as an ultimate conclusion. On the other hand, it is evaluated in terms of acceptability and defeasibility. On this view, an irrelevant argument is either a) an argument that cannot be related to the ultimate conclusion, and thus cannot provide any evidential weight to it (is unacceptable as an argument), or b) an argument that requires more implicit and defeasible inferential steps to support the intended conclusion. In the first case, an irrelevant argument is an (dialogically) incoherent argument, namely a failure to contribute to the shared common goal of the conversation, which can be intentional (aimed at introducing ambiguity or avoiding the conversation) or unintentional (misunderstanding of the goal of the conversation or the possible purpose of the argument, see Rocci, 2005). In the second case, the argument incurs higher defeasibility, as more steps involve higher possibility of being subject to default if the implicit premises conflict with the shared ones. In this case, irrelevant arguments are regarded as arguments grounded on unacceptable or unaccepted and unsupported 


\section{Walton \& Macagno}

premises, leading to conflicts resolved by disregarding the new contradictory and unsupported propositions.

Relevance is modeled using the profiles of dialogue. Previous applications of the profiles technique modeled a profile of dialogue as a sequence of questions and answers in a dialogue, such as a persuasion dialogue where the goal is to resolve an initial conflict of opinions set at the opening stage (Krabbe, 1992; Walton, 1989b). The novelty of this new application of the profiles tool to helping to solve problems of relevance is that it uses argument graphs of the kind that can be integrated with formal and computational argumentation systems such as CAS. In particular, a new kind of node, the rounded rectangular node is incorporated into the argument graph to represent the asking of questions about relevance by one party in a dialogue in response to such a question.

In this new version of the profiles method, rounded rectangular nodes containing question marks indicating points in the sequence of argumentation where relevance questions can appropriately be asked in response to some prior move by the other party appear within the descriptive graph. These are shown in figures 3, 4, and 8 . The rounded rectangular nodes pose relevance questions such as 'What does that prove?' or 'Where is this line of argument going?'. The answer is supposed to be given by the other party who inputs a sequence of argumentation filling the gap in the descriptive graph. The output is a normative graph which is essentially a graph-theoretic argument diagram, and in this paper we have used the CAS argument mapping tool to show how such a diagram is to be constructed. The advantage of this way of modeling the normative graph is that CAS has an argument construction function, and even a Find Arguments assistant that can be adapted to helping a user find a sequence of argumentation leading from premises and conclusions in a knowledge base to some particular proposition designated as the conclusion to be proved.

The analysis of the four examples in the paper has important implications for any attempt to build a theory of relevance. These implications can be summed up in the following ten points.

1. Topical relevance needs to be contrasted with probative relevance. Subject-matter relevance has already been modeled (by relatedness logic — see Walton, 1982). Consider the two propositions 'Bananas are yellow' and 'Over 20,000 bananas were imported from Honduras to Ontario in 2015'. The subject matter of the one proposition overlaps with that of the other, because both are about bananas. Hence the one proposition is topically relevant to the other. However, the two propositions are not proba- 
tively relevant to each other, because you can't prove or disprove the first one from the second one or vice versa. For example, even though it may be true that over 20,000 bananas were imported from Honduras to Ontario in 2015, the truth of that proposition does not support or attack the proposition that bananas are yellow. These two propositions could possibly be relevant to each other if some implicit premises or argument links were found such that when added to the sequence of argumentation that one could be relevant to the other conditionally on the assumption of these additional premises links. But when the two propositions are taken by themselves, the one is not probatively relevant to the other.

2. A contrast needs to be made between direct and indirect relevance. Indirect relevance can span over a lengthy sequences of argumentation or dialogue. Direct relevance refers to a case where there is a single argument from a set of premises to a conclusion. Indirect relevance refers to a case where there is a sequence of arguments with more than two arguments joined together. In this type of case the conclusion of one argument is a premise in another (an argumentation chain). Or in another kind of case it can refer to an adjacent dialogue move, such as a question and reply. Generally indirect relevance refers to the kind of case where there is a large argument graph with an ultimate conclusion at the root of the tree structure. It is in this kind of case where the profiles tool is especially helpful. Making a profile of dialogue to pinpoint a problem of relevance by zooming into some selected smaller part of the large argument graph makes the problem able to be formulated better and easier to solve, as illustrated by the four examples in this paper.

3. Propositions (as well as arguments) can be relevant to each other. This is shown by examples treated in the paper.

4. A premise in an argument can be relevant or irrelevant to that argument. This is shown by examples treated in the paper.

5. A conclusion in an argument can be relevant or irrelevant. This is shown by examples treated in the paper.

6. Dialogue moves in a dialogue can be relevant to each other, for example in question-reply relevance. For example, in an interview a reply to a question may fail to answer the question, or even fail to be relevant to the question.

7. A careful distinction needs to be drawn between relevance simpliciter and conditional relevance. One does not imply the 
other. Most importantly, even though there is a path of argumentation leading from a particular argument by a sequence of other arguments to an ultimate conclusion, the particular argument can fail to be relevant because one or more of its premises are false.

8. A big problem is to build a general theory of relevance that can capture both direct and indirect relevance in problematic real cases of irrelevance such as those illustrated in this paper. This paper clearly does not accomplish this goal, but it takes an important step to it by showing how to apply the profiles method to examples to help test for relevance. Hence we maintain that our paper has significant implications for the larger project of defining relevance in general and for classifying different kinds of relevance.

9. Arguments are often claimed to commit fallacies of relevance when they do not carry enough probative weight to be worth considering, especially in light of other more important arguments with greater probative weight. A corollary of this view is that arguments can be placed in an ordering showing more probative weight or less probative weight. Another implication of this view is that arguments can be more or less relevant. This can be shown by examining the list of fallacies of relevance defined in (Walton, 2004a) and (Walton \& Macagno, 2017).

10. We conjecture as a hypothesis that it makes sense (on our view) to say that evidence can be relevant or irrelevant. Evidence for or against a hypothesis always carries probative weight (by definition-see Walton, 2016), but in some cases a piece of evidence may only carry very little probative weight. This way viewing relevance fits in with the conception of relevance in the Federal Rules of Evidence, as mentioned in our paper above.

Further research is needed to examine many more examples where there are problems of relevance using the new method of profiles of dialogue proposed in this paper. The aim should be to see if the graph-theoretic model of relevance proposed in the paper can be applied to a range of new examples illustrating relevance problems that range from easier ones to harder ones. The first two examples studied in this paper, the coffee example and the Windsor example, seemed initially like they should be easy. But deeper analysis using the new method of profiles showed that they are not as easy as they looked at the beginning. The other two examples, the bank robbery example and the tuna fish example, illustrate characteristic problems of a higher order of difficulty, so called wicked problems. The bank 
robbery example illustrates a problem of posing and replying to objections of relevance in a legal setting, a trial in which there may even be specific legal rules in a given jurisdiction providing criteria for judging relevance. Of course, evaluations of relevance are distinctively different in a legal setting, because there is a judge who makes rulings on whether an argument, or the introduction of any kind of evidence in the trial, is to be excluded as inadmissible on grounds of relevance. Problems of relevance in such settings are easier to manage, stricter, and better organized, because lawyers in a trial commonly make relevance objections, and judges have to respond to them decisively, based on the rules of evidence and other legal guidelines applicable in a given jurisdiction.

The tuna fish example was the most difficult one of all, first of all because it occurred in a parliamentary debate, a setting where the rules governing relevance are not formulated as precisely they are in a trial setting, and where the Speaker has less authority to cut off a line of argumentation that may not seem to be going anywhere. As the tuna fish example illustrates, the Member of Parliament, when asked the question to show where this line of argumentation is going, has the possibility of responding by making a clever connection between two issues that gives the appearance of answering the relevance question. This case shows that answering the question, 'Where is this line of argumentation going?' may solicit a response that is a severe challenge for the profiles method to evaluate. Nonetheless, it was shown that this new version of the profiles method can even be applied successfully to such a vexing case with interesting and revealing results.

Acknowledgements: Douglas Walton would like to thank the Social Sciences and Humanities Research Council of Canada for Insight Grant 435-2012-0104. Fabrizio Macagno would like to thank the Fundação para a Ciência e a Tecnologia for the research grants no. IF/00945/2013, PTDC/IVC-HFC/1817/2014, and PTDC/MHC-FIL/0521/2014.

\section{References}

Asher, N., \& Lascarides, A. (2003). Logics of conversation. Cambridge: Cambridge University Press.

Barth, E. M., \& Krabbe, E. (1982). From axiom to dialogue: A philosophical study of logics and argumentation. Berlin: Walter de Gruyter. 


\section{Walton \& Macagno}

Blakemore, D. (2002). Relevance and linguistic meaning: The semantics and pragmatics of discourse markers. Cambridge: Cambridge University Press.

Blass, R. (1990). Relevance relations in discourse: A study with special reference to Sissala. Cambridge: Cambridge University Press.

Braet, A. (1999). Aristotle's almost unnoticed contribution to the doctrine of stasis. Mnemosyne, 52(4), 408-433.

Carston, R. (2004). Relevance theory and the saying/implicating distinction. In L. Horn \& G. Ward (Eds.), The Handbook of Pragmatics (pp. 633-656). Oxford: Blackwell.

Cicero, M. T. (1988). De Inventione. (C. D. Yonge, Ed.) (The Oratio). London: George Bell \& Sons.

Copi, I., \& Cohen, C. (2005). Introduction to logic, 12th edition. Upper Saddle River: Prentice-Hall.

Dascal, M. (1992). On the pragmatic structure of conversation. In H. Parret \& J. Verschueren (Eds.), (On) Searle on conversation (pp. 35-57). Amsterdam-Philadelphia: John Benjamins Publishing.

Dascal, M. (2003). Interpretation and understanding. Amsterdam: John Benjamins Publishing Company.

Dascal, M., \& Katriel, T. (1979). Digression: A study in conversational coherence. In J. Petofi (Ed.), Text vs. sentence (pp. 76-95). Hamburg: Helmut Buske Verlag.

Giora, R. (1985). Notes towards a theory of text coherence. Poetics Today, 6(4), 699-715.

Giora, R. (1997). Discourse coherence and theory of relevance: Stumbling blocks in search of a unified theory. Journal of Pragmatics, 27(1), 17-34.

Gordon, T. (2010). An overview of the Carneades argumentation support system. In C. Reed \& C. W. Tindale (Eds.), Dialectics, dialogue and argumentation. An examination of douglas Walton's theories of reasoning and argument (pp. 145-156). London: College Publications.

Hamblin, C. L. (1970). Fallacies. London: Methuen.

Harary, F. (1969). Graph Theory. Menlo Park: Addison-Wesley.

Heath, M. (1994). The substructure of stasis-theory from Hermagoras to Hermogenes. The Classical Quarterly, 44(1), 114-129.

Hobbs, J. R. (1979). Coherence and coreference. Cognitive Science, 3, 67-90. http://doi.org/10.1207/s15516709 $\operatorname{cog} 0$ 30144

Hobbs, J. R. (1985). On the coherence and structure of discourse. Stanford: Report No. CSLI-85-37, Center for the Study of Language and Information. 
Hohmann, H. (1989). Dynamics of Stasis: Classical Rhetorical Theory and Modern Legal Argumentation, The. Am. J. Juris., 34, 171-197.

Holdcroft, D. (1987). Conversational relevance. In J. Verschueren \& M. Bertuccelli-Papi (Eds.), The Pragmatic Perspective (pp. 477-495). Amsterdam-Philadelphia: John Benjamins Publishing Company.

Johnson, R., \& Blair, A. (1983). Logical Self-Defence. Toronto: McGraw-Hill Ryerson.

Kellermann, K., \& Sleight, C. (1989). Coherence: A meaningful adhesive for discourse. In J. Anderson (Ed.), Annals of the International Communication Association (pp. 95-129). New York: Routledge.

Kennedy, G. (1963). The art of persuasion in ancient Greece. Princeton: Princeton University Press.

Krabbe, E. C. W. (1992). So what? Profiles for relevance criticism in persuation dialogues. Argumentation, 6(2), 271-283.

Krabbe, E. C. W. (1999). Profiles of dialogue. In J. Gerbrandy, M. Marx, M. de Rijke, \& Y. Venema (Eds.), JFAK: Essays Dedicated to Johan van Benthem on the Occasion of his 50th Birthday (Vol. 3, pp. 25-36). Amsterdam: Amsterdam University Press.

Lascarides, A., \& Asher, N. (1993). Temporal interpretation, discourse relations and commonsense entailment. Linguistics and Philosophy, 16, 437-493. http://doi.org/10.1007/BF009 86208

Lewis, D. (1979). Scorekeeping in a language game. Journal of Philosophical Logic, 8(1), 339-359. http://doi.org/10.1007/ BF00258436

Macagno, F. (2008). Dialectical relevance and dialogical context in Walton's pragmatic theory. Informal Logic, 28(2), 102128.

Macagno, F. (2011). The presumptions of meaning: Hamblin and equivocation. Informal Logic, 31(4), 367-393.

Macagno, F., \& Bigi, S. (2017a). Analyzing the pragmatic structure of dialogues. Discourse Studies, 19(3).

Macagno, F., \& Bigi, S. (2017b). Understanding misunderstanding: Presuppositions and presumptions in doctor-patient chronic care consultations. Intercultural Pragmatics, 14.

Macagno, F., \& Walton, D. (2014). Emotive language in argumentation. New York: Cambridge University Press.

Mauet, T. (2005). Trials: strategy, skills, and the new power of persuasion. New York: Aspen.

McGuire, W. J. (1960). A syllogistic analysis of cognitive relationships. In M. Rosenber, C. Hovland, W. McGuire, R. Abelson, \& J. Brehm (Eds.), Attitude organization and change (pp. 65-111). New Haven: Yale University Press. 
McGuire, W. J. (1966). The current status of cognitive consistency theories. In S. Feldman (Ed.), Cognitive consistency: Motivational antecedents and behavioral consequents (pp. 126). New York: Academic Press.

Nadeau, R. (1959). Classical systems of stases in Greek: Hermagoras to Hermogenes. Greek, Roman and Byzantine Studies, 2(1), 51-71.

Petty, R., \& Cacioppo, J. (1986). The elaboration likelihood model of persuasion. Advances in Experimental Social Psychology, (19), 123-189.

Petty, R., Rucker, D., Bizer, G., \& Cacioppo, J. (2004). The elaboration likelihood model of persuasion. In J. Seiter \& R. Gass (Eds.), Perspectives on persuasion, social influence and compliance gaining (pp. 65-89). Boston: Allyn \& Bacon.

Pullman, G. L. (1995). Deliberative rhetoric and forensic stasis: Reconsidering the scope and function of an ancient rhetorical heuristic in the aftermath of the Thomas/Hill controversy. Rhetoric Society Quarterly, 25(1-4), 223-230.

Reed, C., Walton, D., \& Macagno, F. (2007). Argument diagramming in logic, law and artificial intelligence. The Knowledge Engineering Review, 22(1), 87. http://doi.org/10.1017/S0269888907001051

Rocci, A. (2005). Are manipulative texts coherent? Manipulation, presuppositions, and (in-) congruity. Manipulation and Ideologies in the Twentieth Century: Discourse, Language, Mind. (Discourse Approaches to Politics, Society and Culture 17), 1, 85-112.

Scheuer, O., Loll, F., Pinkwart, N., \& McLaren, B. M. (2010). Computer-supported argumentation: A review of the state of the art. International Journal of Computer-Supported Collaborative Learning, 5(1), 43-102.

Sperber, D., \& Wilson, D. (1986). Relevance: Communication and Cognition. Oxford: Blackwell.

Sperber, D., \& Wilson, D. (1995). Relevance: Communication and Cognition (Vol. 1). Oxford: Blackwell Publishing Ltd.

Taboada, M. (2009). Implicit and explicit coherence relations. In J. Renkema (Ed.), Discourse, of Course: An overview of research in discourse studies (pp. 127-140). AmsterdamPhiladelphia: John Benjamins Publishing.

Van Dijk, T. (1976). Sentence Topic and Discourse Topic. Papers in ShvicPhilology, 1, 49-61.

Van Dijk, T. (1977). Semantic macro-structures and knowledge frames in discourse comprehension. In M. A. Just \& P. Carpenter (Eds.), Cognitive processes in comprehension (pp. 332). Hillsdale, NJ, NJ: Lawrence Erlbaum Associates.

Walton, D. (1982). Topical relevance in argumentation. Amsterdam-Philadelphia: John Benjamins Publishing Company. 
Walton, D. (1989a). Informal logic. New York: Cambridge University Press.

Walton, D. (1989b). Question-reply argumentation. Westport: Greenwood Press.

Walton, D. (1992). Which of the fallacies are fallacies of relevance? Argumentation, 6(2), 237-250.

Walton, D. (1998). The New Dialectic. Conversational contexts of argument. Toronto: University of Toronto Press.

Walton, D. (1999). Profiles of dialogue for evaluating arguments from ignorance. Argumentation, 13(1), 53-71.

Walton, D. (2004a). Classification of fallacies of relevance. Informal Logic, 24(1), 183-185. Retrieved from http://ojs.uwindsor.ca/ojs/leddy/index.php/informal_logic/arti cle/view/2133

Walton, D. (2004b). Relevance in argumentation. AmsterdamPhiladelphia: John Benjamins Publishing Company.

Walton, D. (2015). Profiles of Dialogue: A Method of Argument Fault Diagnosis and Repair, Argumentation and Advocacy, 52(2), 91-108.

Walton, D. (2016). Argument evaluation and evidence. Cham: Springer.

Walton, D., \& Gordon, T. (2012). The Carneades model of argument invention. Pragmatics \& Cognition, 20(1), 1-26. http://doi.org/10.1075/pc.20.1.01wal

Walton, D., \& Krabbe, E. (1995). Commitment in dialogue. Albany: State University of New York Press.

Walton, D., \& Macagno, F. (2007). Types of dialogue, dialectical relevance and textual congruity. Anthropology \& Philosophy, 8(1-2), 101-119.

Walton, D., \& Macagno, F. (2017). Straw man and the strategic uses of interpretation. In A. Capone (Ed.), Perspectives in Pragmatics, Philosophy, Psychology. Cham: Springer.

Walton, D., Reed, C., \& Macagno, F. (2008). Argumentation schemes. New York: Cambridge University Press.

Wilson, D. (1998). Discourse, coherence and relevance: A reply to Rachel Giora. Journal of Pragmatics, 29(1), 57-74.

Wilson, D., \& Matsui, T. (1998). Recent approaches to bridging: Truth, coherence, relevance. UCL Working Papers in Linguistics, 10, 173-200.

Wilson, D., \& Sperber, D. (2004). Relevance theory. In L. Horn \& G. Ward (Eds.), Handbook of Pragmatics (pp. 607-632). Oxford: Blackwell. http://doi.org/10.1016/j.pragma.2009.09 .021

Ziv, Y. (1988). On the rationality of "relevance" and the relevance of "rationality." Journal of Pragmatics, 12(5), 535545. 